\title{
(2) OPEN ACCESS \\ Association between air pollution and lung development in schoolchildren in China
}

\author{
Tao Wang $\mathbb{D}^{1}{ }^{1}$ Haitao Wang, ${ }^{1}$ Jian Chen, ${ }^{2}$ Jiansheng Wang, ${ }^{3}$ Dunqiang Ren, ${ }^{4}$ Wei Hu, \\ Hongmei Wang, ${ }^{4}$ Wei Han, ${ }^{5}$ Shuguang Leng, ${ }^{1}$ Rong Zhang, ${ }^{6}$ Yuxin Zheng ${ }^{1}$
}

\begin{abstract}
- Additional material is published online only. To view please visit the journal online (http://dx.doi.org/10.1136/ jech-2020-214283)
\end{abstract}

For numbered affiliations see end of article.

\section{Correspondence to} Yuxin Zheng, School of Public Health, Qingdao University, 308 Ningxia Road, Qingdao 266071, China;

yxzheng@qdu.edu.cn

TW, HW, and JC contributed equally.

SL, RZ and YZ co-supervised the study.

Received 6 April 2020 Revised 13 May 2020 Accepted 23 May 2020
Check for updates

(C) Author(s) (or their employer(s)) 2020. Re-use permitted under CC BY-NC No commercial re-use. See rights and permissions. Published by BMJ.

To cite: Wang $\mathrm{T}$, Wang $\mathrm{H}$,

Chen J, et al. J Epidemiol

Community Health

2020:74:792-798.

\begin{abstract}
Background China has been facing nationwide air pollution at unprecedented high levels primarily from fossil-fuel combustion in the past decade. However, few studies have been conducted on the adverse effect of severe air pollution on lung development in school-age children.

Methods Using wellness check and air pollution data from 2014 to 2017, we conducted a retrospective analysis of lung development in 21616 school-age children from Shijiazhuang and Qingdao from North China with severe vs mild air pollution. Linear mixed effects model was performed to assess the effect of air pollution on forced vital capacity (FVC) growth.
\end{abstract}

Results Exposure to severe air pollution was associated with a dramatic reduction in annual FVC growth rate $(-71.3 \mathrm{~mL}, \quad \mathrm{p}<0.001)$. In addition, every $10 \mu \mathrm{g} / \mathrm{m}^{3}$ increase in annual $\mathrm{PM}_{2.5}$ level was associated with a reduction of annual FVC growth by $12.2 \mathrm{~mL}(p<0.001)$. Sex discrepancy (boys vs girls) in FVC growth was greater in Qingdao (35.4 mL/year, 95\% Cl: 26.0 to 44.7) than in Shijiazhuang (19.8 mL/year, 95\% Cl: 9.3 to 30.3) (p for interaction=0.063). Exposure to indoor coal- or woodburning stove heating $(-79.4 \mathrm{~mL}, \mathrm{p}<0.001)$ and secondhand smoke at home $(-59.3 \mathrm{~mL}, \mathrm{p}=0.003)$ were inversely associated with FVC growth.

Conclusion Our study raised serious alarm over the threat of severe air pollution to lung development in school-age children. Sex discrepancy in lung development was reduced dramatically in heavily polluted area.

\section{INTRODUCTION}

Ambient and indoor air pollution are the world's most detrimental threat to children's health and are also major causes for global inequality and environmental injustice. ${ }^{1}$ In China, residents have been exposed to nationwide air pollution at unprecedented high levels primarily from fossil-fuel combustion due to rapid urbanisation and industrialisation in the past two decades. $^{2-4}$ In 2016, 81\% of Chinese were living in places where the concentrations of particulate matter with aerodynamic diameters $<2.5 \mu \mathrm{m}\left(\mathrm{PM}_{2.5}\right)$ were higher than the Interim Target-1 limit $\left(35 \mu \mathrm{g} / \mathrm{m}^{3}\right)$ set by the WHO. ${ }^{5}$ Although humans of all ages could be affected by air pollution exposure, children are disproportionately affected because their lungs and immune systems are developing, and they are more active in environments with high levels of pollutants relative to adults. ${ }^{17}$

Forced vital capacity (FVC) reflects the total compliance from both the lung and the chest wall and serves as a common indicator of lung development in children. ${ }^{8}$ Compromised lung development in early life due to air pollution will not only affect the overall lung health at childhood but also be a predisposition factor for acquisition of chronic obstructive pulmonary disease and its associated diseases such as lung cancer and cardiovascular diseases at a later time. ${ }^{9} 10$ Studies conducted in East Europe and North America with low levels of air pollution had identified evidence supporting adverse effects of long-term air pollution exposure on children's FVC level. ${ }^{11-15}$ However, question remains whether severe air pollution as seen in most cities in China affects the lung development in school-age children and if yes to what extent.

In this study, we assessed the association between long-term effect of ambient air pollution and lung development in 21616 children aged 6-12 years from two big cities located in North China using data extracted from the Program of Physical Wellness Examination in School-age Children from 2014 to 2017. The effect of air pollution on sex discrepancy in lung development was analysed. Finally, the indoor air pollution sources were also explored with regard to their association with lung development in less polluted areas for identification of modifiable risk factors.

\section{METHODS}

\section{Selection of study cities}

The study protocol was approved by the Institutional Review Board of Qingdao University. Two big cities located in North China Plain with similar latitude and comparable Human Development Index (0.757 0.822) were selected. ${ }^{16}$ City A (Shijiazhuang City) from Hebei Province was one of the most polluted cities in North China, with seasonal $\mathrm{PM}_{2.5}$ levels ranging from 45 to $220 \mathrm{mg} / \mathrm{m}^{3}$ between 2014 and 2017 . City B (Qingdao City) from Jiaodong Peninsula was one of the least polluted cities in North China, with seasonal $\mathrm{PM}_{2.5}$ levels ranging from 22 to $92 \mathrm{mg} / \mathrm{m}^{3}$ between 2014 and 2017 (figure 1 and online supplementary table $\mathrm{S} 1$ ).

\section{Acquisition of physical wellness data}

This cross-sectional survey was conducted from May to December 2018 in five and seven primary schools in urban areas of City A and City B and included 10 655 and 10961 primary school students, respectively. The deidentified data including date of examination, age, sex, height, weight, FVC and grade for 21616 children aged 6-12 years between 2014 and 2017 were extracted from the Program of Physical Wellness Examination in School-age Children upon 

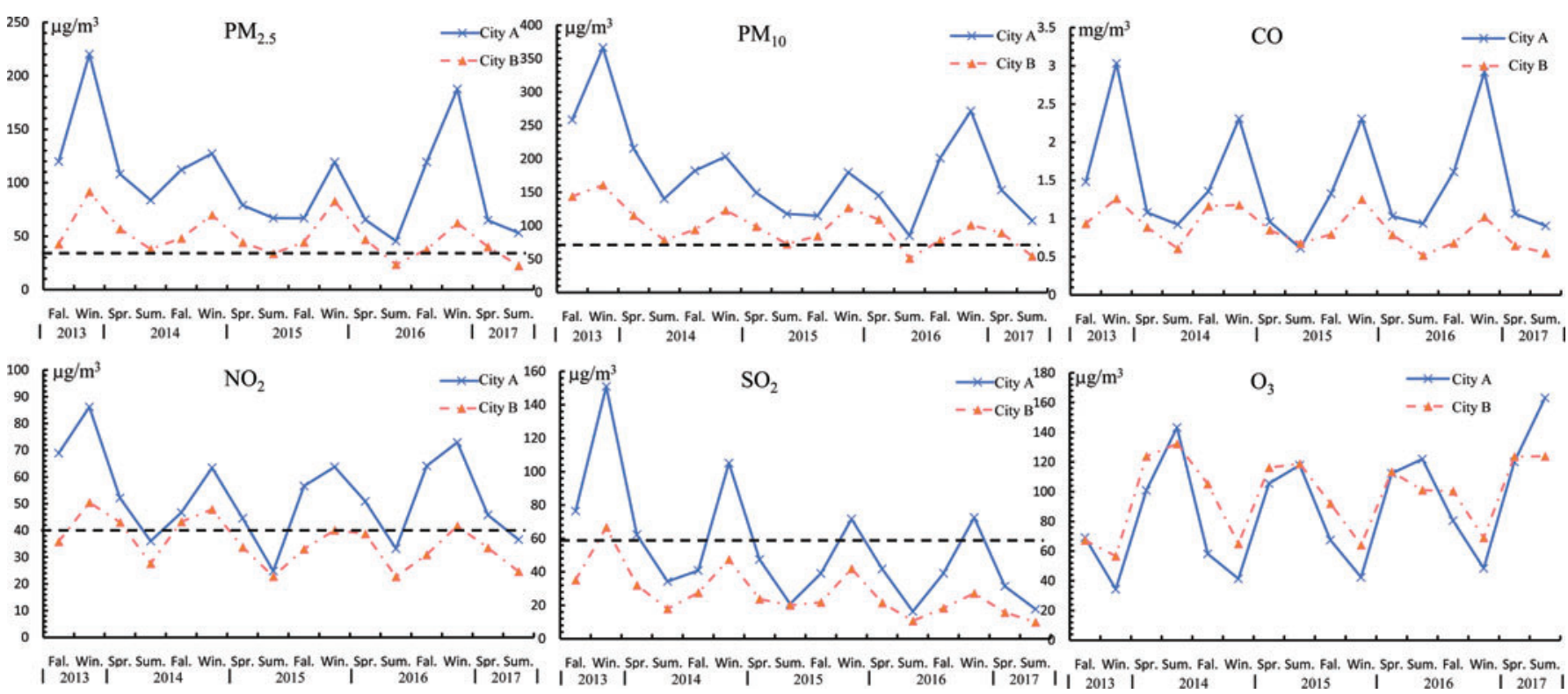

Figure 1 Seasonal average levels of $\mathrm{PM}_{2.5}, \mathrm{PM}_{10}, \mathrm{CO}, \mathrm{NO}_{2}, \mathrm{SO}_{2}$ and $\mathrm{O}_{3}$ in City A versus City B. Blue solid line represents City $\mathrm{A}$, red solid line represents City $\mathrm{B}$, black-dashed line denotes the Grade II criteria set by the China's ambient air quality standards. The annual average concentration limits of $\mathrm{PM}_{2.5}, \mathrm{PM}_{10}, \mathrm{NO}_{2}$ and $\mathrm{SO}_{2}$ are $35 \mu \mathrm{g} / \mathrm{m}^{3}, 70 \mu \mathrm{g} / \mathrm{m}^{3}, 40 \mu \mathrm{g} / \mathrm{m}^{3}$ and $60 \mu \mathrm{g} / \mathrm{m}^{3}$, respectively. $\mathrm{CO}$ and $\mathrm{O}_{3}$ have no annual average concentration limit in $\mathrm{China}$. $\mathrm{CO}$, carbon monoxide; Fal., fall; $\mathrm{NO}_{2}$, nitrogen dioxide; $\mathrm{O}_{3}$, ozone; $\mathrm{SO}_{2}$, sufur dioxide; Spr., spring; Sum., summer; Win., winter.

approval by municipal Centers for Disease Control and Prevention of each participating city. The board determined that consenting was not necessary.

In order to assess the effects of outdoor and indoor air pollution on FVC growth and respiratory symptoms, a questionnaire adapted from the Children's Questionnaire recommended by the American Thoracic Society (ATS-DLD-78-C) ${ }^{17}$ was used to obtain relevant information in nine schools from City A and City B. The questionnaire was completed by children's parents or legal guardians, and the overall participation rate was $98 \%$ among the nine schools. A total of 9118 students completed the questionnaire. There were 2019 participants from City A and the mean age was 9.3 years and 7099 participants from City B and the mean age was 8.8 years. The annual wellness check results between 2014 and 2017 from students who returned the questionnaire were acquired by retrieving the original medical records archived at the school nurse offices. Written consent was provided by a parent or legal guardian for all study participants who returned the questionnaires. Detailed information was available in online supplemental methods.

\section{FVC measurement}

The spirometry was conducted at schools by registered nurses according to the Technical Standard for Physical Examination for Students (GB/T 26 343-2010) that adopted a similar procedure from the European Respiratory Society/American Thoracic Society guideline for spirometry. FVC was mandatorily measured every year for all children, and the participation rate was more than $98 \%$. A detailed description of the procedure is available in supplemental methods.

\section{Outdoor air pollution data}

The real-time hourly concentrations of $\mathrm{PM}_{2.5}$, particulate matter with aerodynamic diameters $<10 \mu \mathrm{m}\left(\mathrm{PM}_{10}\right)$, carbon monoxide (CO), nitrogen dioxide $\left(\mathrm{NO}_{2}\right)$, sulfur dioxide $\left(\mathrm{SO}_{2}\right)$ and ozone $\left(\mathrm{O}_{3}\right)$ in the study areas between 2014 and 2017 were acquired from China National Environmental Monitoring Center and were used to compute the annual average concentrations in each city. Detailed information was available in online supplemental methods.

\section{Indoor air pollution data}

The indoor air pollution data were assessed by our questionnaire with several items, for example, exposure to secondhand smoking, method of indoor heating during winter and other exposures.

\section{Statistical analysis}

An analytical plan was developed during the study design stage to assess the project hypotheses. First, the linear mixed effects (LME) model with a subject-specific random intercept was used to assess the effect of outdoor air pollution on FVC growth by including an interaction term between time and air pollution (eg, City A vs City B, number of non-attainment days, or PM levels). Variable 'time' is time since enrollment (TSE). Fixed effects of baseline age, sex, height and body mass index (BMI) were included in each model. Second, a three-way interaction term among air pollution, sex and TSE was included in the LME model to assess whether the sex discrepancy in FVC growth differed or not between the two cities. Third, LME models were used to examine the effect of indoor air pollution on FVC growth by including an interaction team between individual indoor environmental factors and TSE in students from City B who completed the questionnaire. This analysis was only conducted in City B with a much cleaner background in terms of outdoor air pollution because we were concerned that the weaker effect of indoor air pollution might be disguised in an area with high background of outdoor air pollution. Finally, logistic regression was used to assess the difference of respiratory symptoms and illnesses between these two cities. All statistical analyses were conducted in SAS 9.4 (site 70239 492). 


\section{RESULTS}

Air pollution level in City A versus City B between 2014 and 2017

A clear seasonal fluctuation was observed for all pollutants (figure 1 and online supplementary table S1). City A always had higher levels of air pollutants except $\mathrm{O}_{3}$ compared with City B. The number of non-attainment days for air pollutants was also much higher in City A than that in City B during the entire study window, with $\mathrm{PM}_{2.5}$ and $\mathrm{PM}_{10}$ as the major air pollutants beyond Ambient Air Quality Standards of China in both cities (online supplementary table S2). Spearman correlation and principal component analyses were used to characterise the coexisting pattern of major air pollutants. $\mathrm{PM}_{2.5}$ correlated highly with $\mathrm{PM}_{10}, \mathrm{CO}, \mathrm{SO}_{2}$ and $\mathrm{NO}_{2}$, with correlation coefficients ranging from 0.59 to 0.90 , reflecting the common origin of these species (online supplementary table S3). Similar correlation pattern among air pollutants was also identified between the two cities, suggesting that the difference in air pollution between these two cities may be more of quantity rather than type (not shown).

\section{Characteristics of the study subjects}

This study included 10655 and 10961 primary school students with available information on the longitudinal spirometry measurements from two studied cities (online supple mentary table S4). The demographic data of 9118 children whose parents completed the questionnaires are also summarised in online supplementary table S4. The absolute difference in studied demographic variables was trivial.

\section{Association between outdoor air pollution and FVC growth}

Compared with those from City B, children from City A had a reduced level of FVC at baseline $(-158.4 \mathrm{~mL}, 95 \% \mathrm{CI}:-169.1$ to $-147.6, p<0.001)$ and a reduced FVC growth rate over time $(-71.3 \mathrm{~mL} /$ year, 95\% CI: -78.4 to $-64.2, \mathrm{p}<0.001$, table 1 and figure $2 \mathrm{~A})$. In addition, annual average $\mathrm{PM}_{2.5}$ and $\mathrm{PM}_{10}$ levels were regressed with FVC growth to further quantify the effect of PM exposure. Each $10 \mu \mathrm{g} / \mathrm{m}^{3}$ increase in $\mathrm{PM}_{2.5}$ and $\mathrm{PM}_{10}$ levels was associated with a reduction of $12.2 \mathrm{~mL} / \mathrm{year}$ (95\% CI: 11.0 to $13.4, \mathrm{p}<0.001)$ and $8.1 \mathrm{~mL} /$ year $(95 \% \mathrm{CI}$ : 7.4 to $8.9, \mathrm{p}<0.001$ ) in FVC growth rate, respectively (table 1 ). Moreover, every 10 non-attainment days in $\mathrm{PM}_{2.5}$ was associated with a lower FVC growth rate by $6.4 \mathrm{~mL} /$ year $(95 \% \mathrm{CI}: 5.8$ to 7.0, $\mathrm{p}<0.001$, online supplementary table S5).
Effect of outdoor air pollution on the sex discrepancy of FVC growth

As given in online supplementary table $\mathrm{S} 6$ and figures $2 \mathrm{~B}$ and $2 \mathrm{C}$, sex discrepancy (boys vs girls) in FVC growth was greater in City B (35.4 mL/year, 95\% CI: 26.0 to 44.7$)$ than in City A $(19.8 \mathrm{~mL} /$ year, $95 \%$ CI: 9.3 to 30.3 ), suggesting boys might be particularly vulnerable to pulmonary effects of air pollution.

\section{Effect of indoor air pollution factors on FVC growth}

In children who were frequently exposed to secondhand tobacco smoke at home, FVC growth was significantly reduced by $59.7 \mathrm{~mL} /$ year (95\% CI: 19.0 to $100.4, \mathrm{p}=0.004)$ compared with those who were never exposed (table 2). Compared with community-based central boiler heating, gas/electric heating $(-44.5 \mathrm{~mL} /$ year, 95\% CI: -72.7 to $-16.3, \mathrm{p}=0.002)$ and coal/wood-burning stove heating $(-80.1 \mathrm{~mL} /$ year, $95 \% \mathrm{CI}$ : -111.2 to $-49.1, \mathrm{p}<0.001)$ were significantly associated with a reduced FVC growth rate (table 2). We did not find any evidence to support shorter distance to main roads or no use of air purifier indoor as being associated with reduced FVC growth.

\section{Joint effects of outdoor and indoor air pollution on FVC growth} We stratified our subjects into four groups: lower outdoor (City B) and lower indoor (never smoking/smoking less than once a week and central boiler heating) air pollution, lower outdoor (City B) and higher indoor (smoking at least once a week or no central boiler heating) air pollution, higher outdoor (City A) and lower indoor (never smoking/smoking less than once a week and central boiler heating) air pollution, and higher outdoor (City A) and higher indoor (smoking at least once a week or no central boiler heating) air pollution. Compared with lower outdoor and lower indoor air pollution, lower outdoor and higher indoor air pollution $(-21.4 \mathrm{~mL} /$ year, $95 \% \mathrm{CI}:-33.0$ to $-9.9, \mathrm{p}<0.001)$, higher outdoor and lower indoor air pollution $(-85.2 \mathrm{~mL} / \mathrm{year}, 95 \%$ CI: -99.4 to $-71.0, p<0.001)$, and higher outdoor and higher indoor air pollution $(-101.1 \mathrm{~mL} / \mathrm{year}, 95 \% \mathrm{CI}$ : -134.5 to $-67.7, p<0.001)$ were significantly associated with a reduced FVC growth rate (figure 3 ). However, there was no evidence of interaction of outdoor and indoor air pollution on FVC growth $(\mathrm{p}=0.765)$.

\begin{tabular}{|c|c|c|c|c|c|c|}
\hline \multirow[b]{2}{*}{ Parameter } & \multicolumn{2}{|l|}{ City A vs City B } & \multicolumn{2}{|l|}{$\mathrm{PM}_{2.5}$} & \multicolumn{2}{|l|}{$\mathrm{PM}_{10}$} \\
\hline & Estimate $(95 \% \mathrm{Cl})(\mathrm{mL})$ & $P$ value & Estimate $(95 \% \mathrm{Cl})(\mathrm{mL})$ & $P$ value & Estimate $(95 \% \mathrm{Cl})(\mathrm{mL})$ & $P$ value \\
\hline Time & $146.4(140.4,152.3)$ & $<0.001$ & $185.6(175.8,195.5)$ & $<0.001$ & $201.8(190.9,212.8)$ & $<0.001$ \\
\hline Air pollution & $-158.4(-169.1,-147.6)$ & $<0.001$ & $-16.8(-18.5,-15.1)$ & $<0.001$ & $-8.7(-9.7,-7.7)$ & $<0.001$ \\
\hline Timexair pollution & $-71.3(-78.4,-64.2)$ & $<0.001$ & $-12.2(-13.4,-11.0)$ & $<0.001$ & $-8.1(-8.9,-7.4)$ & $<0.001$ \\
\hline Boys & $132.7(123.5,141.9)$ & $<0.001$ & $133.3(124.0,142.6)$ & $<0.001$ & $133.3(124.0,142.6)$ & $<0.001$ \\
\hline BMI & $12.3(11.0,13.6)$ & $<0.001$ & $11.5(10.2,12.8)$ & $<0.001$ & $11.5(10.2,12.8)$ & $<0.001$ \\
\hline Height & $18.4(17.8,19.1)$ & $<0.001$ & $19.1(18.4,19.7)$ & $<0.001$ & $19.2(18.5,19.8)$ & $<0.001$ \\
\hline
\end{tabular}

BMI, body mass index; FVC, forced vital capacity.

The effect of air pollution on FVC growth was assessed by including an interaction term between air pollutant (City A vs City B or PM concentrations) and time since enrollment in the linear mixed effects model in 21616 primary school students. Estimates for $\mathrm{PM}_{2.5}$ and $\mathrm{PM}_{10}$ were calculated based on every $10-\mathrm{mg} / \mathrm{m}^{3}$ increase. 

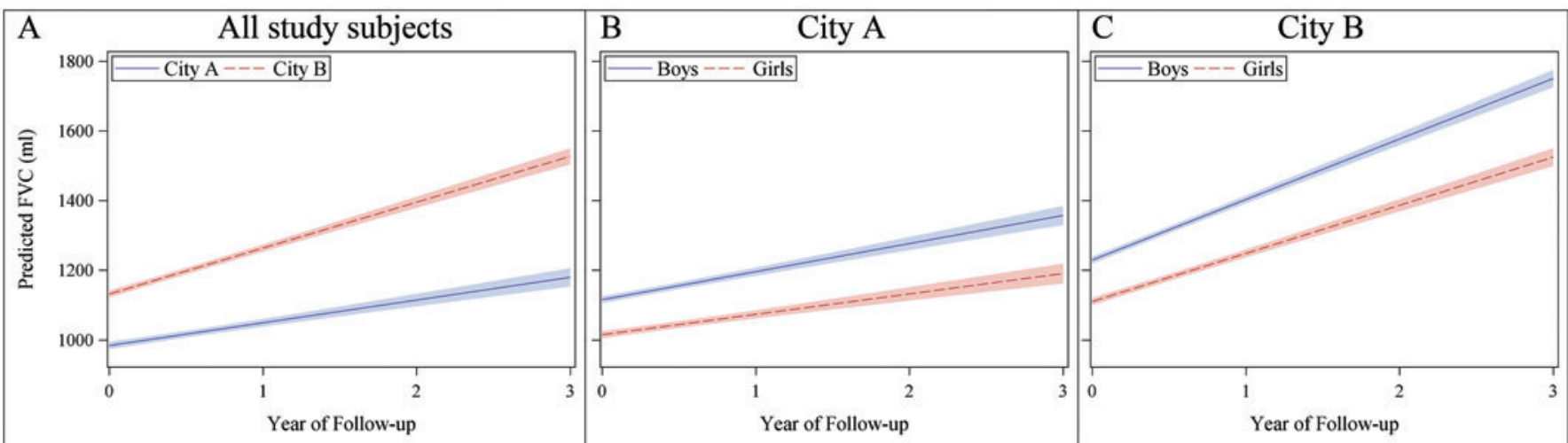

Figure 2 District-specific estimated average growth in FVC (A) and sex discrepancy in lung function growth in City A (B) and City B (C). A: The FVC growth rate in City A was about $71.3 \mathrm{~mL} /$ year $(p<0.001)$ lower than that seen in City B. Estimate and $p$ value were calculated for students who were girls with baseline values of age of 7 years, height of $128 \mathrm{~cm}$ and BMI of 16.2. A three-way interaction among city, sex and TSE was included in the linear mixed effects model to assess whether sex discrepancy in FVC growth was differential between cities. The annual FVC growth rates in girls and boys were $56.2 \mathrm{mLL}$ and $76 \mathrm{~mL}$ in City A, respectively (B). The annual FVC growth rates in girls and boys were $134.5 \mathrm{~mL}$ and $169.8 \mathrm{~mL}$ in City B, respectively (C). The FVC growth advantages in boys versus girls were $19.8 \mathrm{~mL}$ in City $A$ and $35.4 \mathrm{~mL}$ in City $\mathrm{B}(p=0.063)$. Estimate and $p$ value were calculated for students with baseline values of age of 7 years, height of $128 \mathrm{~cm}$ and BMI of 16.2. BMI, body mass index; FVC, forced vital capacity; TSE, time since enrollment.

\section{Prevalence of respiratory diseases and symptoms between the two cities}

Respiratory diseases and symptoms were surveyed in children to assess whether the effect of air pollution on FVC growth was due to higher prevalence of respiratory diseases in City A vs City B (online supplementary table S7). Chronic rhinitis had the highest prevalence $(13.6 \%$ and $18.3 \%$ in City A and City B) followed by asthma (6.4\% and $7.0 \%$ in City A and City B), seasonal cough (5.9\% and $8.1 \%$ in City $\mathrm{A}$ and City B), chronic cough (5.8\% and 5.6\% in City A and City B) and pneumonia (6.0\% and 5.5\% in City A and City B). Interestingly, students in City A had significantly reduced prevalent for seasonal cough (especially in spring and summer) and chronic rhinitis than students in City B (online supplementary table S7). Thus, results did not support that the effect of air pollution on FVC growth is due to a higher prevalence of respiratory diseases or symptoms.

\section{DISCUSSION}

Based on archived children wellness data and national air quality monitoring data with high integrity from years 2014 to 2017, a retrospective analysis was conducted by comparing FVC growth in a large sample of elementary students from urban areas of two vice provincial cities located in North China with mild versus severe air pollution. We found that outdoor and indoor air pollution independently affected lung development in school-age children.

\section{Outdoor air pollution}

Children from City A with severe air pollution had a dramatic reduction in FVC growth rate $(-71.3 \mathrm{~mL} /$ year, 95\% CI: -78.4 to $-64.2, \mathrm{p}<0.001$ ) compared with children from City B, with the level of reduction equivalent to more than one-third of the annual gain in FVC growth (eg, 160-200 mL/year) seen in students from City $\mathrm{B}$ or national survey for reference values of

Table 2 The association between indoor air pollution factors and traffic-related air pollution index and FVC growth (in City B, $\mathrm{n}=7099$ )

\begin{tabular}{|c|c|c|c|c|c|c|}
\hline \multirow[b]{2}{*}{ Environmental factor } & \multirow[b]{2}{*}{ Prevalence } & \multirow{2}{*}{$\begin{array}{l}\text { Time } \\
\text { Estimate }(95 \% \mathrm{Cl})^{*} \\
(\mathrm{~mL})\end{array}$} & \multicolumn{2}{|l|}{ Factor } & \multicolumn{2}{|l|}{ Timexfactor } \\
\hline & & & $\begin{array}{l}\text { Estimate }(95 \% \mathrm{Cl}) \\
(\mathrm{mL})\end{array}$ & $P$ value & $\begin{array}{l}\text { Estimate }(95 \% \mathrm{Cl}) \\
(\mathrm{mL})\end{array}$ & $P$ value \\
\hline \multicolumn{7}{|l|}{ Exposed to secondhand smoke at home (vs never) } \\
\hline Less than once a week & $42.0 \%$ & $173.6(154.0,193.2)$ & $15.4(-21.2,51.9)$ & 0.410 & $-2.7(-25.7,20.4)$ & 0.821 \\
\hline At least once a week & $9.1 \%$ & $173.6(154.0,193.2)$ & $49.4(-16.1,114.9)$ & 0.140 & $-59.7(-100.4,-19.0)$ & 0.004 \\
\hline \multicolumn{7}{|l|}{ Heating type (vs central boiler heating $\dagger$ ) } \\
\hline Gas/electric & $16.2 \%$ & $187.7(169.8,205.6)$ & $84.4(39.5,129.4)$ & $<0.001$ & $-44.5(-72.7,-16.3)$ & 0.002 \\
\hline Coal- or wood-burning stove & $18.9 \%$ & $187.7(169.8,205.6)$ & $72.6(22.7,122.5)$ & 0.004 & $-80.1(-111.2,-49.1)$ & $<0.001$ \\
\hline Air purifier use (vs never) & $23.1 \%$ & $167.6(150.5,184.6)$ & $-16.9(-60.4,26.7)$ & 0.448 & $-0.6(-27.9,26.7)$ & 0.967 \\
\hline Distance from main traffic $<500 \mathrm{~m}$ (vs $\geq 500 \mathrm{~m}$ ) & $41.6 \%$ & $159.7(141.0,178.3)$ & $-9.2(-44.7,26.3)$ & 0.611 & $18.7(-3.6,41.0)$ & 0.101 \\
\hline
\end{tabular}

FVC, forced vital capacity.

Association between indoor air pollution factors and FVC growth was explored using linear mixed effects model with adjustment for baseline age, sex, height, body mass index, family income and mother's education.

${ }^{*} \mathrm{p}<0.001$.

tCommunity-based central boiler heating is a most common heating method in northern China cities that used circulated hot water inside radiators to heat rooms in winter. Hot water around $80^{\circ}$ at the entry of the houses is supplied through pipe network and heated by massive boilers that burn fossil fuel (eg, gas, natural oil or coal) and usually locate close to residential zone. Each massive boiler unit can provide hot water to meet winter heating need for hundreds of families. These massive boilers are of high efficiency and have excellent emission treatment system to minimise its effect on air quality in winter. 


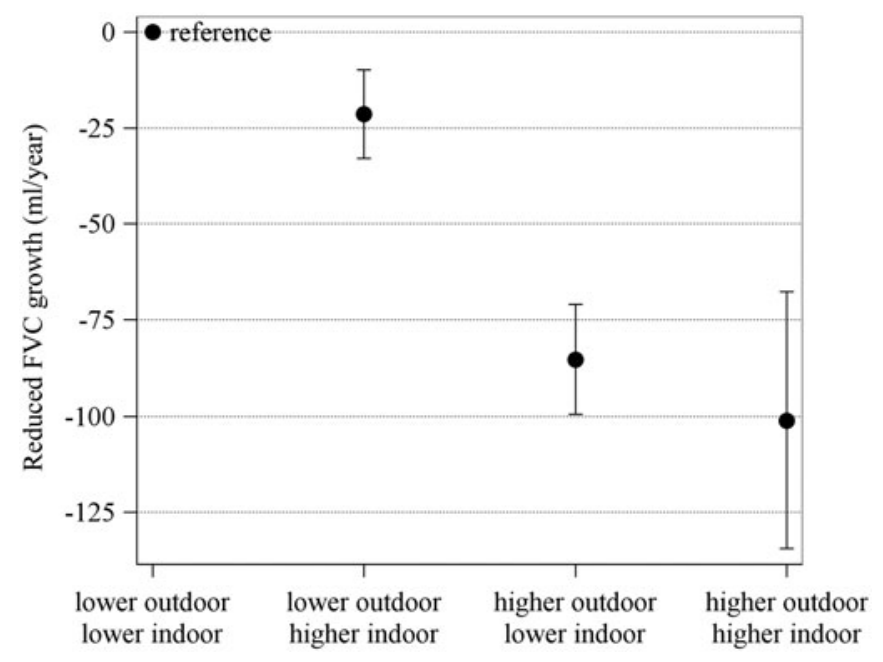

Figure 3 Joint effects of outdoor and indoor air pollution on FVC growth. We stratified our subjects into four groups: lower outdoor (City B) and lower indoor (never smoking/smoking less than once a week and central boiler heating) air pollution (reference), lower outdoor (City B) and higher indoor (smoking at least once a week or no central boiler heating) air pollution, higher outdoor (City A) and lower indoor (never smoking/smoking less than once a week and central boiler heating) air pollution, and higher outdoor (City A) and higher indoor (smoking at least once a week or no central boiler heating) air pollution. Joint effects were explored using LME model with adjustment for baseline age, sex, height, BMI, family income and mother's education. BMI, body mass index; FVC, forced vital capacity; LME, linear mixed effects.

spirometry. ${ }^{18} 19$ We found no evidence to support that the effect of severe air pollution on FVC growth was due to lung illnesses commonly seen in children. Interindividual variation in FVC is primarily attributable to differences in the number of alveoli. ${ }^{12} 20$ Animal studies found that prenatal and postnatal exposure of mice to concentrated urban $\mathrm{PM}_{2.5}$ decreased the number of alveoli and led to altered lung function at an early stage of life potentially through affecting DNA damage and regulation, inflammation and cell proliferation in fetal lungs. ${ }^{21-23}$ Alveoli reduction might be a potential mechanism through which air pollution may impact lung growth. Our findings are of great public health relevance as a dramatic stunt in FVC growth due to severe air pollution exposure in school-age children might lead to a lower maximally attainable lung health in early adulthood that could become a predisposition factor for acquisition of lung ageing problems in later life.

Ambient $\mathrm{PM}_{2.5}$ concentration has been used as a parameter quantifying the association between air pollution and lung health in many epidemiological studies. In our study, every $10-\mu \mathrm{g} / \mathrm{m}^{3}$ increase in annual average $\mathrm{PM}_{2.5}$ level was associated with a reduction of FVC growth by $12.2 \mathrm{~mL} /$ year (95\% CI: 11.0 to 13.4, $\mathrm{p}<0.001)$. The Taiwan Children's Health Study conducted in areas with annual $\mathrm{PM}_{2.5}$ level of $19.3-52.5 \mathrm{mg} / \mathrm{m}^{3}$ found that every $10-\mu \mathrm{g} / \mathrm{m}^{3}$ increase of $\mathrm{PM}_{2.5}$ was associated with an annual deficit in FVC growth by $41.9 \mathrm{~mL} /$ year in boys and $34.0 \mathrm{~mL} /$ year in girls. ${ }^{24}$ The implementation of air qualitycontrol policies in Southern California has gradually reduced the air pollution level, and the Children Health Study found that every $10-\mu \mathrm{g} / \mathrm{m}^{3}$ decrease in $\mathrm{PM}_{2.5}$ could accelerate FVC growth by $25.2 \mathrm{~mL} /$ year, with starting regional $\mathrm{PM}_{2.5}$ level lingering around $18-34 \mathrm{mg} / \mathrm{m}^{3} .{ }^{25}$ The smaller effect observed in our study might be caused by a higher level of air pollution leading to a different dose-response curve and different sources of air pollution (heating in winter vs traffic-related yearlong) leading to different constituents carried by the PM and subsequently different pulmonary toxicity. However, it is important to note that a cohort study of 3273 children aged 6-12 years from four Chinese cities of Chongqing, Guangzhou, Lanzhou and Wuhan with annual average $\mathrm{PM}_{2.5}$ level of $50-150 \mathrm{mg} / \mathrm{m}^{3}$ between 1993 and 1996 identified that every $10-\mu \mathrm{g} / \mathrm{m}^{3}$ increase in quarterly average of $\mathrm{PM}_{2.5}$ was associated with a reduction of only $1.5 \mathrm{~mL} /$ year in FVC growth rate. ${ }^{26}$ Their results may be biased by the large variation in income and lifestyle between regions, mixing the South and North China cities with strikingly different winter heating patterns in one study and lack of daily air quality data.

We also found evidence that FVC growth in boys was much more vulnerable to the adverse effect of air pollution compared with girls. A similar pattern was identified in the Taiwan Children's Health Study that the $\mathrm{PM}_{2.5}$ 's adverse effect on FVC growth in boys was $23 \%$ worse than that seen in girls. ${ }^{24}$ The exact mechanisms underlying this sex discrepancy are unclear; however, this may implicate boys spending more time outdoors and being more physically active, ${ }^{27}$ inherited differences in lung structure and airway development ${ }^{112829}$ and differences in sex hormones regulating lung development. ${ }^{29-31}$ Thus, in future, delineation of the molecular mechanism underlying the observed sex discrepancy for adverse effect of air pollution on lung development may receive high priorities for research.

\section{Indoor air pollution}

Secondhand cigarette smoke and solid fuel for domestic heating in winter are two major sources of indoor air pollution and have been linked to many health problems. We found that frequent exposure to secondhand cigarette smoke at home and use of coal/wood-burning stove as major indoor heating source in winter season were associated with a reduction of $60-80 \mathrm{~mL} /$ year in FVC growth in children, a level of retardation in lung development comparable with that caused by exposure to severe outdoor air pollution. Researches have shown that households that allow indoor smoking or use of coal- or wood-burning stoves for cooking and winter heating have dramatically increased levels of PM that are comparable with or much worse than the air pollution scenario currently seen in Beijing's winter. ${ }^{32-35}$ This finding is of great public health importance as well because these two factors have a relatively high prevalence in the studied population (9.1-17.1\%) and can also be relatively easily intervened through parenthood smoking cessation plan and improvement of winter heating appliance and ventilation at home.

\section{CONCLUSIONS}

In summary, the findings of our study raised serious alarm over the threat of severe air pollution to lung development in schoolage children. Children living in the heavily polluted city lost onethird of the FVC growth compared with children from the city with mild air pollution, despite that the air pollution level in the reference city in this study was already twofold to ninefold over the WHO recommended 'safe level'. Moreover, boy's advantage in lung development was reduced dramatically in heavily polluted areas. Considering the large number of children living in many cities with moderate-to-severe air pollution in China, this young generation with compromised lung health before adulthood may pose a heavy burden on individual health and even national social security later due to increased predisposition for 
acquisition of ageing-related pulmonary and extrapulmonary diseases. Thus, the data urge Chinese government to take a more aggressive action on its air pollution mitigation policy and to protect children from adverse effects of outdoor and indoor air pollution.

\section{What is already known on this subject}

- Studies conducted in East Europe and North America with low levels of air pollution had identified evidence supporting adverse effects of long-term air pollution exposure on children's FVC level.

- However, question remains whether severe air pollution as seen in most cities in China affects the lung development in school-age children and if yes to what extent.

\section{What this study adds}

- Exposure to severe air pollution caused a reduction in annual FVC growth rate equivalent to one-third of annual FVC growth seen in school-age children living in less polluted or clean areas in China.

- FVC growth in boys was much more vulnerable to the adverse effect of air pollution compared with girls.

- Exposure to indoor coal- or wood-burning stove heating and secondhand smoke at home was two modifiable risk factors for preservation of FVC growth in children.

- The data urge Chinese government to take a more aggressive action on its air pollution mitigation policy and to protect children (age $6-12$ years) from adverse effects of outdoor and indoor air pollution.

\section{Author affiliations}

'Department of Occupational and Environmental Health, School of Public Health, Qingdao University, Qingdao, China

${ }^{2}$ Department of School Health, Qingdao Municipal Center for Disease Control and Prevention, Qingdao, China

${ }^{3}$ Policy Research Center for Environment and Economy, Ministry of Ecology and Environment of the People's Republic of China, Beijing, China

${ }^{4}$ Department of Respiratory and Critical Care Medicine, The Affiliated Hospital of Qingdao University, Qingdao, China

${ }^{5}$ Department of Respiratory and Critical Care Medicine, Qingdao Municipal Hospital Group, Qingdao, China

${ }^{6}$ Department of Toxicology, School of Public Health, Hebei Medical University,

Shijiazhuang City, China

Correction notice This article has been corrected since it first published online. The contributor statement has been corrected.

Contributors TW: Formal analysis, methodology, visualisation, data curation, writing - original draft. HW: investigation. JC: investigation. JW: investigation. DR: formal analysis. WH: investigation. HW: formal analysis. WH: formal analysis. SL: funding acquisition, supervision, writing—review \& editing. RZ: investigation, writing-review \& editing. YZ: funding acquisition, supervision, writing - review editing editing.

Funding This study was sponsored by the National Natural Science Foundation of China [91643203, 91943301, 81872600] and Guangdong Provincial Natural Science Foundation Team Project [2018B030312005]. The study funders had no role in the design and conduct of the study; collection, management, analysis and interpretation of the data; preparation, review or approval of the manuscript; or decision to submit the manuscript for publication.

Competing interests None declared.

Patient consent for publication Not required.

Ethics approval and consent to participate This study obtained the approval of the Institutional Review Board of Qingdao University.

Data sharing statement Data are available upon reasonable request.
Provenance and peer review Not commissioned; externally peer reviewed.

Open access This is an open access article distributed in accordance with the Creative Commons Attribution Non Commercial (CC BY-NC 4.0) license, which permits others to distribute, remix, adapt, build upon this work non-commercially, and license their derivative works on different terms, provided the original work is properly cited, appropriate credit is given, any changes made indicated, and the use is noncommercial. See: http://creativecommons.org/licenses/by-nc/4.0/.

\section{ORCID iD}

Tao Wang http://orcid.org/0000-0002-5910-8775

\section{REFERENCES}

1 Perera F. Pollution from fossil-fuel combustion is the leading environmental threat to global pediatric health and equity: solutions exist. Int J Environ Res Public Health 2017;15:16

2 Yan B, Liu S, Zhao B, et al. China's fight for clean air and human health. Environ Sci Technol 2018;52:8063-4.

3 Zhang Y, Lang J, Cheng S, et al. Chemical composition and sources of PM1 and PM 2.5 in Beijing in autumn. Sci Total Environ 2018;630:72-82.

4 Lang J, Li S, Cheng S, et al. Chemical characteristics and sources of submicron particles in a city with heavy pollution in China. Atmosphere 2018;9:388.

5 Dong GH. Ambient air pollution in China. Respirology 2019;24:626-7.

6 Song $\mathrm{C}, \mathrm{He}$ J, Wu L, et al. Health burden attributable to ambient $\mathrm{PM}_{2.5}$ in China. Environ Pollut 2017;223:575-86.

7 Gilliland FD. Outdoor air pollution, genetic susceptibility, and asthma management: opportunities for intervention to reduce the burden of asthma. Pediatrics 2009; 123:S168-73.

8 Forno E, Han YY, Mullen J, et al. Overweight, obesity, and lung function in children and adults-a meta-analysis. J Allergy Clin Immunol Pract 2018;6:e10.

9 Lange P, Celli B, Agusti A, et al. Lung-function trajectories leading to chronic obstructive pulmonary disease. N Engl J Med 2015;373:111-22.

10 Goldizen FC, Sly PD, Knibbs LD. Respiratory effects of air pollution on children. Pediatr Pulmonol 2016;51:94-108.

11 Peters JM, Avol E, Gauderman WJ, et al. A study of twelve Southern California communities with differing levels and types of air pollution - II. Effects on pulmonary function. Am J Respir Crit Care Med 1999:159:768-75.

12 Gauderman WJ, Avol E, Gilliland F, et al. The effect of air pollution on lung development from 10 to 18 years of age. N Engl J Med 2004;351:1057-67.

13 Schultz ES, Gruzieva O, Bellander T, et al. Traffic-related air pollution and lung function in children at 8 years of age: a birth cohort study. Am J Respir Crit Care Med 2012:186:1286-91.

14 Schultz ES, Hallberg J, Bellander T, et al. Early-life exposure to traffic-related air pollution and lung function in adolescence. Am J Respir Crit Care Med 2016;193:171-7.

15 Hoek G, Pattenden S, Willers S, et al. PM 10 , and children's respiratory symptoms and lung function in the PATY study. Eur Respir J 2012:40:538-47.

16 UNDP. China sustainable cities report 2016: Measuring Ecological Input and Human Development 2016. Avaliable https://www.cn.undp.org/content/china/en/home/ library/democratic_governance/china-sustainable-cities-report-2016-measuring-ecological-input.html (accessed 7 Jun 2020)

17 Ferris BG. Epidemiology standardization project (American Thoracic Society). Am Rev Respir Dis 1978:118(6 Pt 2):1-120.

18 Wang $X$, Dockery DW, Wypii D, et al. Pulmonary function growth velocity in children 6 to 18 years of age. Am Rev Respir Dis 1993;148:1502-8.

19 Jian W, Gao Y, Hao C, et al. Reference values for spirometry in Chinese aged 4-80 years. J Thorac Dis 2017;9:4538-49.

20 Ochs M, Nyengaard JR, Jung A, et al. The number of alveoli in the human lung. Am J Respir Crit Care Med 2004;169:120-4.

21 de Barros Mendes Lopes T, Groth EE, Veras M, et al. Pre- and postnatal exposure of mice to concentrated urban PM decreases the number of alveoli and leads to altered lung function at an early stage of life. Environ Pollut 2018;241:511-20.

22 Cui L, Shi L, Li D, et al. Real-ambient particulate matter exposure-induced cardiotoxicity in C57/B6 mice. Front Pharmacol 2020;11:199.

23 Li D, Zhang R, Cui L, et al. Multiple organ injury in male C57BL/6J mice exposed to ambient particulate matter in a real-ambient PM exposure system in Shijiazhuang, China. Environ Pollut (Barking, Essex: 1987). 2019; 248: 874-87.

24 Hwang BF, Chen YH, Lin YT, et al. Relationship between exposure to fine particulates and ozone and reduced lung function in children. Environ Res 2015;137:382-90.

25 Gauderman WJ, Urman R, Avol E, et al. Association of improved air quality with lung development in children. N Engl J Med 2015;372:905-13.

26 Roy A, Hu W, Wei F, et al. Ambient particulate matter and lung function growth in Chinese children. Epidemiology 2012;23:464-72.

27 Gao Y, Chan EY, Li LP, et al. Chronic effects of ambient air pollution on lung function among Chinese children. Arch Dis Child 2013;98:128-35.

28 Schultz ES, Litonjua AA, Melen E. Effects of long-term exposure to traffic-related air pollution on lung function in children. Curr Allergy Asthma Rep 2017;17:41.

29 Carey MA, Card JW, Voltz JW, et al. It's all about sex: gender, lung development and lung disease. Trends Endocrinol Metab 2007;18:308-13. 
30 Carey MA, Card JW, Voltz JW, et al. The impact of sex and sex hormones on lung physiology and disease: lessons from animal studies. Am J Physiol Lung Cell Mol Physiol 2007;293:L272-8.

31 Fuentes N, Roy A, Mishra V, et al. Sex-specific microRNA expression networks in an acute mouse model of ozone-induced lung inflammation. Biol Sex Differ 2018;9:18.

32 Semple S, Apsley A, Azmina Ibrahim T, et al. Fine particulate matter concentrations in smoking households: just how much secondhand smoke do you breathe in if you live with a smoker who smokes indoors? Tob Control 2015;24:e205-11.
33 Butz AM, Breysse P, Rand C, et al. Household smoking behavior: effects on indoor air quality and health of urban children with asthma. Matern Child Health J 2011;15:460-8.

34 Jin Y, Zhou Z, He G, et al. Geographical, spatial, and temporal distributions of multiple indoor air pollutants in four Chinese provinces. Environ Sci Technol 2005;39:9431-9.

35 Hu W, Downward GS, Reiss B, et al. Personal and indoor PM 2.5 exposure from burning solid fuels in vented and unvented stoves in a rural region of China with a high incidence of lung cancer. Environ Sci Technol 2014;48:8456-64. 